\title{
Atividade antimicrobiana da geoprópolis da abelha jataí (Tetragonisca angustula) contra bactérias isoladas em leite de vacas mestiças leiteiras com mastite
}

(Antimicrobial activity of bee geopropolis of jataí (Tetragonisca angustula) against bacteria isolated from crossbred cows milk with mastitis)

Cintia Raye Maciel, Carlos Augusto Constancio Bastos, Roberta Rollemberg Cabral Martins, Denise de Mello Bobany ${ }^{1}$

1CCorrespondência: cintiaraye@yahoo.com.br

RESUMO: A mastite é responsável por perdas consideráveis aos produtores e às indústrias. A utilização de terapias convencionais tem resultado em resistência por parte dos microrganismos além de resíduos eliminados no leite, interferindo na produção de laticínios e na saúde pública. Na busca por terapias alternativas, particularmente os apiterápicos tem demonstrado bons resultados frente a diferentes microrganismos causadores de enfermidades. Em um experimento com 10 amostras de leite de animais positivos ao teste de CMT onde sete apresentaram crescimento bacteriano, verificou-se a eficácia in vitro da geoprópolis da abelha Jataí (Tetragonisca angustula) contra bactérias patogênicas isoladas e identificadas nessas amostras como Stapylococcus sp. coagulase-negativos.

Palavras-chave: apiterapia; bovinos; doença da mama; própolis

ABSTRACT: The mastitis is responsible for considerable losses to the producers and to the industries. The use of conventional therapies has been made resistance for part of the microorganisms besides residues found in the milk, interfering in the production of dairy products and in the public health. The demand of alternative therapies, particularly the apiterapy, has been demonstrating good results in front of different microorganisms which caused illnesses. In a experiment with 10 samples of milk of positive animals to the CMT test when seven presented bacterial growth, it was found the efficiency in vitro of the geopropolis of the bee Jatai (Tetragonisca angustula) against Stapylococcus sp. coagulase-negatives.

Key Words: apitherapy; bovine; breast disease; propolis 


\section{INTRODUÇÃO}

O leite consiste em uma das principais fontes de proteína para a população humana e, devido a isso, há uma preocupação constante com a sua qualidade. A mastite, definida como a inflamação da glândula mamária, considerada, sob 0 ponto de vista econômico, como a doença mais relevante de bovinos leiteiros em todos os continentes, exerce influência extremamente prejudicial sobre a composição e sobre as características físico-químicas deste produto (Costa et al. 2008).

A etiologia complexa e multivariada da mastite composta, principalmente, por Staphylococcus coagulase positivos, Streptococcus Corynebacterium agalactiae, Staphylococcus coagulase negativos entre outros, transmitidos, principalmente, durante a ordenha (Yamamura et al. 2007; Costa, 2008) exige um controle rigoroso no sentido da erradicação desses microorganismos contagiosos e a manutenção de baixos índices de mastite ambiental (Müller, 2002; Ribeiro et al. 2009).

O tratamento ideal da mastite seria aquele que eliminasse todos os processos infecciosos do úbere sem qualquer alteração no leite (Pinto, 2000; Pinto et al, 2001; Nader Filho et al. 2007), já que, de acordo com Batista et al. (2008) e Ribeiro et al. (2009), o resíduo de drogas antimicrobianas pode gerar um impacto no desenvolvimento de bezerras alimentadas com leite de vacas em tratamento podendo surgir, ao longo do tempo, resistência bacteriana e/ou reações adversas.

Desse modo, a demanda por novas formas de criações utilizando um manejo voltado para prevenção de doenças e que preconize 0 uso de terapêuticas mais suaves, como as terapias alternativas, são consideradas, se contrapondo aos modelos convencionais de criação com a utilização de medicamentos alopáticos (Honorato, 2006). As terapias alternativas, economicamente viáveis, socialmente justas e ambientalmente corretas podem gerar uma relação equilibrada entre os fatores ambientais, socioculturais e econômicos (Villavicencio et al. 2007; Costa; Araújo, 2009).

A apicultura é considerada uma das atividades agrícolas que mais crescem no Brasil nas últimas décadas se tornando uma das que mais realiza a inclusão social no setor agropecuário, aliando crescimento e expansão da produção apícola à utilização desses produtos para uso terapêutico (Trovo; Silva; Leão, 2003).

Dentre os produtos das abelhas, do gênero Apis, mais conhecidos destacam-se o mel e a própolis, essa última já bastante utilizada para diferentes fins terapêuticos, com ações antimicrobianas, anti-inflamatórias, anticarinogênicas (Duarte et al. 2003), antitumorais, citotóxicas (Torres et al. 2008), antivirais (Lustosa et al. 2008), antioxidantes, imunomodulatórias e antiúlceras (Sousa et al. 2007) devidamente comprovadas.

De acordo com Loguercio et al. (2006) o extrato de própolis possui efeito antimicrobiano em $90,5 \%$ das amostras bacterianas testadas, contra Staphylococcus coagulase-positivo e Streptococcus sp., isolados em casos de mastite bovina, possuindo efeitos superiores à antimicrobianos comumente utilizados para tratamento dessa enfermidade. Silva et al. (2008) concluíram, após isolamento bacteriano de microrganismos patogênicos em mastite, que a própolis possui capacidade de inibir o crescimento da Pasteurella sp. e Staphylococcus coagulase-positivo e Borges et al. (2014) encontraram cerca de $75 \%$ da atividade inibitória do controle-positivo 
(gentamicina) frente ao Staphylococcus aureus e Staphylococcus sp..

Abelhas sem ferrão produzem geoprópolis, com as mesmas funções na colmeia que a própolis das Apis como vedação de colmeias e proteção de ninhos (Dutra et al. 2008) e uma espécie de abelha indígena sem ferrão (Tetragonisca angustula) popularmente conhecida como abelha Jataí, é particularmente interessante pois, segundo Miorim et al. (2003), a geoprópolis e o mel dessa abelha possuem atividades antimicrobianas contra bactérias da espécie Staphylococcus aureus, efeitos atribuídos a diversos compostos polifenólicos que possui (Sousa et al. 2007; Lustosa et al., 2008).

Conforme resultados observados por Silva et al. (2008), a geoprópolis da espécie Melipona subnitida, da mesma família que a Tetragonisca angustula inibiu o crescimento de Bacillus sp., Pasteurella sp., Pseudomonas sp., Stahylococcus coagulase-negativa e Staphylococcus coagulase-positiva isolados em leite de vacas com mastite subclínica.

Este trabalho tem como objetivo verificar in vitro a atividade antibacteriana da geoprópolis da abelha Jataí (Tetragonisca angustula) contra bactérias patogênicas isoladas em leite de vacas com mastite.

\section{MATERIAL E MÉTODOS}

\section{Procedência e coleta das amostras}

As amostras de leite foram obtidas de 10 vacas de um rebanho localizado na Propriedade Rancho Ferradura, no município do Carmo, estado do Rio de Janeiro. A criação era formada por animais mestiços, de várias idades, criados em sistema semiintensivo, utilizando ordenha manual e em diferentes estágios de lactação.
Antes da ordenha as vacas foram submetidas à limpeza dos tetos com água e sabão, secas com papel toalha e submetidas ao processo de antissepsia com álcool $70 \%$. Posteriormente cada teto foi imerso em álcool iodado a $10 \%$ e, em seguida, desprezado o primeiro jato. Foram colhidas 40 amostras de leite, correspondendo aos quatro tetos de cada vaca e realizado o California Mastitis Test (CMT) kit Faetec, de acordo com a recomendação do fabricante, para identificação dos tetos comprometidos pela mastite. No intervalo entre os testes, era feita a desinfecção da raquete com água e sabão neutro e secagem com papel toalha.

Dos animais positivos, foram coletadas amostras com aproximadamente $10 \mathrm{~mL}$ de leite, referentes aos 10 tetos mais acometidos, em tubos estéreis, previamente identificados com o nome do animal e respectivo quarto. Dentre essas amostras, duas apresentaram reação leve $(+)$, cinco apresentaram reação moderada $(+\quad+)$ e três apresentaram reação intensa $(+++)$ de acordo com a viscosidade observada no Teste de CMT. Essas amostras foram acondicionadas em isopor com gelo e encaminhadas ao Laboratório de Microbiologia Veterinária do Centro Universitário Serra dos Órgãos UNIFESO.

\section{Isolamento e identificação dos microrganismos \\ Uma porção (referente a uma} alçada) de cada uma das 10 amostras foi semeada em tubos de ensaio contendo meio de cultura Triptona Soja Caldo (TSB) e incubados em estufa bacteriológica a $37^{\circ} \mathrm{C}$ por 24 horas, a fim de se observar o crescimento de microrganismos. Posteriormente as colônias obtidas foram submetidas à bacterioscopia (Método de Gram) para evidenciação dos microrganismos 
através da observação das características morfo-tintoriais.

Após a identificação de bactérias do gênero Staphylococcus sp., foram feitas repicagens em placas de Petri contendo meio de cultura Chapman, sendo incubadas a $37^{\circ} \mathrm{C}$ por 24 horas, a fim de obter culturas puras para realização de testes antibiograma. Foi realizado novo teste de Gram para confirmação do isolamento bacteriano.

\section{Teste de coagulase}

Após isolamento do Staphylococcus sp., realizou-se o teste de coagulase onde foram coletadas de 2-4 colônias referentes a cada amostra isolada em meio de cultura Chapman e colocadas em tubo de ensaio juntamente com $0,5 \mathrm{~mL}$ de plasma de coelho com EDTA pipetados com pipeta estéril, a fim de observar formação de coágulos. Os tubos foram colocados em estufa bacteriológica a $37^{\circ} \mathrm{C}$ durante 1 hora.

O teste foi repetido em lâmina colocando-se uma porção (referente a uma alçada) de solução salina juntamente com 2-4 colônias referentes a cada uma das amostras presentes em meio Chapman e uma porção de plasma de coelho com EDTA com o mesmo objetivo, fazendo-se uma análise imediata.

\section{Repicagem para TSB}

Foi coletada uma colônia de cada amostra isolada em meio de cultura Chapman e feita repicagem para tubos de ensaio contendo meios TSB para obter culturas jovens para realização do antibiograma.

\section{Coleta e diluição da geoprópolis}

O recolhimento da geoprópolis foi feito no apiário Serrano, em Teresópolis, a partir da raspagem das colmeias de Tetragonisca angustula, principalmente nas paredes internas próximas a tampa, acondicionados em um frasco estéril com tampa de borracha e, imediatamente, encaminhado ao Laboratório de Microbiologia Veterinária do UNIFESO.

O extrato de geoprópolis foi formulado a partir da metodologia descrita por Park et al. (1998) a $80 \%$ com zona de inibição de $1,5 \mathrm{~mm}$ de crescimento microbiano.

\section{Preparo dos discos com extrato de geoprópolis}

Os discos de papel de filtro $(5 \mathrm{x}$ $1 \mathrm{~mm}$ de diâmetro) foram obtidos artesanalmente, esterelizados em estufa e impregnados com 0 extrato de geoprópolis, permanecendo em repouso em placa de Petri lacradas com fita isolante durante 15 minutos para, posteriormente, serem mantidos em estufa a $60^{\circ} \mathrm{C}$ durante 4 horas para eliminação de qualquer resíduo etanólico de acordo com Park et al. (1998).

\section{Antibiograma}

Para esse teste foi utilizado o Ágar Mueller-Hinton contido em tubos de ensaio devidamente esterelizados, submetidos à fusão e mantidos em banho-maria a $50^{\circ} \mathrm{C}$ para permanecerem em estado líquido. Posteriormente, foram adicionados $0,1 \mathrm{~mL}$ da cultura contida em TSB, referentes a cada amostra, em cada tubo contendo o Ágar Mueller-Hinton, submetidos à homogeneização e vertidos em placas de Petri devidamente identificadas. Após a solidificação do meio contendo a cultura do Staphylococcus sp., foram colocados, em cada placa, 4 discos de papel contendo o extrato de geoprópolis e as mesmas incubadas a $37^{\circ} \mathrm{C}$ por 24 horas a fim de fazer a leitura a partir da medição do halo de sensibilidade. 


\section{RESULTADOS E DISCUSSÃO}

Após 24 horas da semeadura pode-se observar presença de turvação nos meios de cultura TSB onde se cultivaram as amostras, o que indicou crescimento microbiano (Figura1).

A bacterioscopia (teste de Gram) permitiu, por meio da visualização das características morfo-tintoriais a identificação de Staphylococcus sp. em todas as amostras analisadas (Figura 2).

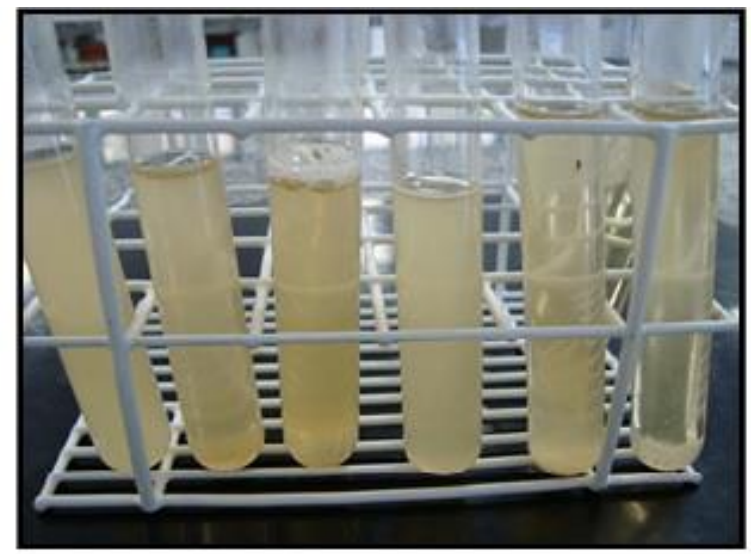

Figura 1- Crescimento microbiano indicado pela turvaçăo em meio de culturaTSB.

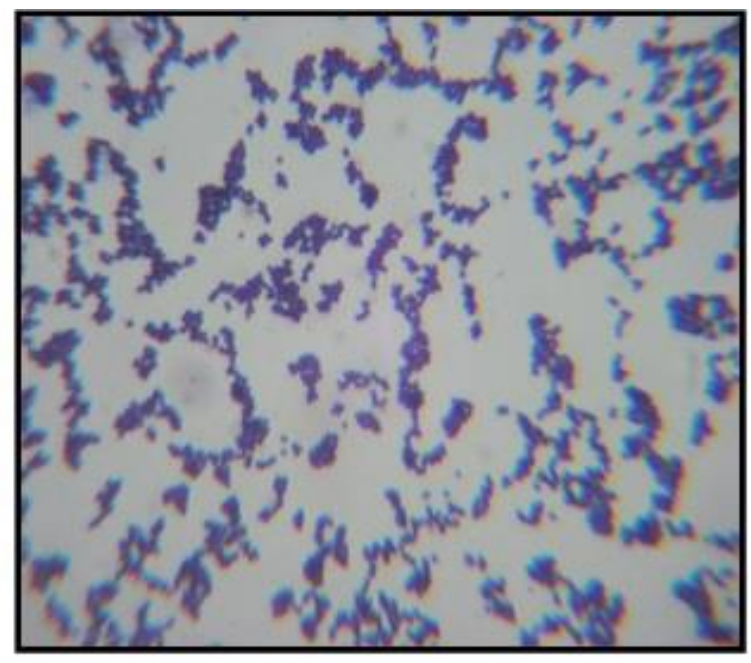

Figura 2 - Fotomicrografia demonstrando a presença do Staphylococcus $s p$. presente no leite de vacas mastíticas.

Da semeadura em meio de cultura Chapman observou-se crescimento bacteriano em 7 das 10 amostras após 24 horas de incubação a $37^{\circ} \mathrm{C}$ (Figura 3 ), fato que pode ser justificado por nem sempre haver crescimento microbiano em amostras positivas ao teste de CMT devido a que o agente patogênico não esteja sendo eliminado de forma contínua dando resultado falso negativo, de acordo com Ribeiro et al. (2003). Novamente podese confirmar, através da bacterioscopia, a presença de Staphylococcus sp.

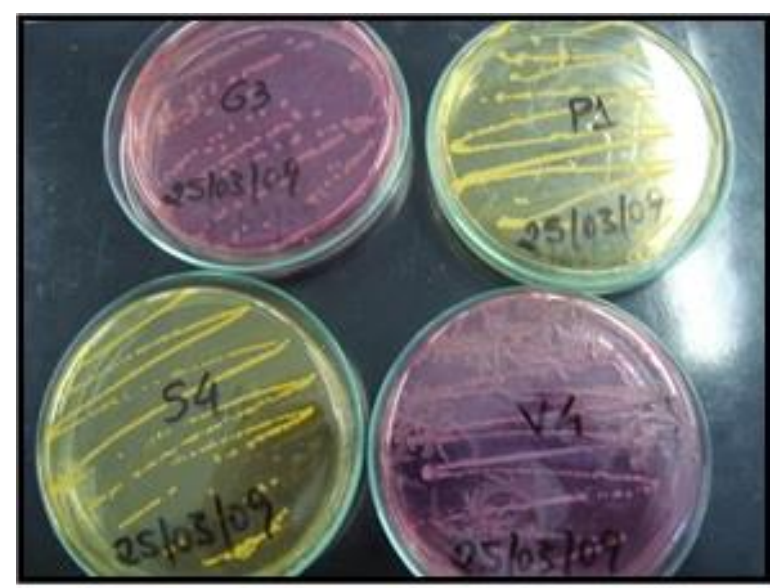

Figura 3 - Crescimento bacteriano em meio de cultura Chapman.

No teste de coagulase não foram observadas formações de coágulos em nenhuma das amostras analisadas, caracterizando, portanto, o Staphylococcus sp. coagulase-negativo. Os tubos retornaram à estufa por mais uma hora para confirmação do resultado novamente dando negativo. A repetição do teste de coagulase em lâmina obteve o mesmo resultado.

A repicagem para meio TSB e a confirmação em lâmina demonstraram o mesmo resultado negativo caracterizando 0 Staphylococcus coagulase-negativo que, de acordo com Yamamura et al. (2007) e Costa (2008), é uma das bactérias mais comuns na forma subclínica da doença.

$\mathrm{Na}$ realização do antibiograma, não se observou a formação de halo de inibição nas 7 amostras analisadas, sugerindo que o extrato de geoprópolis não fosse eficaz contra bactérias do gênero Staphylococcus coagulasenegativa, embora Sousa et al. (2007) e 
Lustosa et al. (2008) tenham constatado essa ação.

Devido a isso, foi realizado novo antibiograma onde a metodologia referente ao preparo dos discos foi modificada. Esses não foram submetidos à estufa a $60^{\circ} \mathrm{C}$ por 4 horas, e sim impregnados com extrato de geoprópolis e colocados diretamente nas placas de Petri contendo a cultura microbiológica em Ágar Mueller-Hinton. Outros discos de papel foram impregnados com álcool de cereais a $96 \%$ funcionando como controle. As placas de Petri foram colocadas em estufa a $37^{\circ} \mathrm{C}$ por 24 horas com $\mathrm{O}$ objetivo de observar a formação de halo de inibição. Novamente não se observou sensibilidade do Staphylococcus coagulase-negativa ao extrato alcoólico de geoprópolis, o que suscita a necessidade mais testes.

Diante dos resultados negativos anteriores, uma nova metodologia foi adotada na tentativa de confirmar a resistência do Staphylococcus coagulase-negativa frente ao extrato de geoprópolis da abelha Jataí e novos repiques da cultura bacteriana em questão foram feitos, a fim de realizar o antibiograma em meio líquido.

Após 24 horas de incubação a $37^{\circ} \mathrm{C}$ e confirmação do crescimento bacteriano pelo Método de Gram, as amostras foram novamente repicadas, cada uma em dois tubos de ensaio contendo, o primeiro, $1,0 \mathrm{~mL}$ e 0 segundo, $0,5 \mathrm{~mL}$ de extrato de geoprópolis e encubados a $37^{\circ} \mathrm{C}$ por mais 24 horas a fim de observar se houve, ou não, crescimento bacteriano.

Passadas 24 horas, novos repiques foram feitos referentes aos tubos contendo $1,0 \mathrm{~mL}$ e $0,5 \mathrm{~mL}$ de extrato de geoprópolis em meio de cultura TSB com o objetivo de observar crescimento microbiano. Após 24 horas de incubação em estufa a $37^{\circ} \mathrm{C}$ não foi possível observar qualquer turvação no meio, o que sugere a ausência de microorganismos (Figura 4), o que foi confirmado na bacterioscopia por meio do Teste de Gram onde não foi observada a existência do Staphylococcus coagulase-negativa (Figura 5).

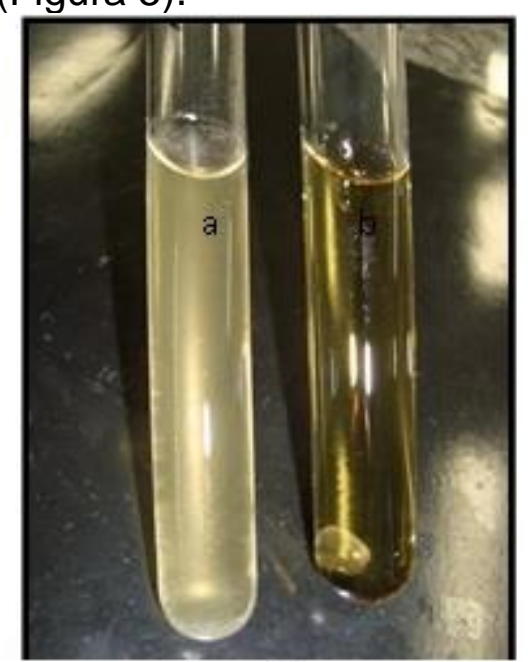

Figura-4-Comparação do antibiograma com aspecto turvo (a) em relação uma cultura mi crobiana com aspecto límpido (b).

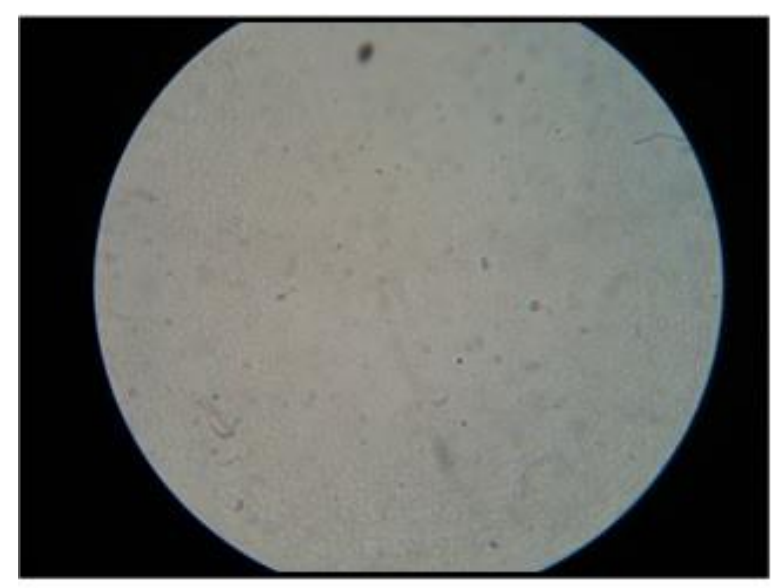

Figura 5 - Bacterioscopia revelando a ausência de Staphylococcus coagulase-negativa.

Nesse teste, houve eficácia do extrato de geoprópolis de Tetragonisca angustula frente bactérias Staphylococcus coagulase-negativa, a semelhança da geoprópolis de outras abelhas indígenas como a Melipona subnitida, efetiva contra várias bactérias, particularmente 0 Staphylococcus coagulase-negativa presente em mastite bovina testada por Silva et al. (2008). 
A diversidade de resultados encontrados frente às diferentes metodologias aplicadas na confecção do antibiograma leva a hipótese de que algo interferiu durante a impregnação dos discos de papel e sua colocação sobre o Ágar Mueller-Hinton contendo a cultura bacteriana. Possivelmente, a presença de algum composto na geoprópolis da abelha Tetragonisca angustula pode ter interferido na impregnação dos discos, já que, quando o extrato do geoprópolis foi colocado em meio líquido, sua eficácia antimicrobiana foi demonstrada, provavelmente devido à possibilidade de sua expansão por toda cultura bacteriana.

\section{CONCLUSÃO}

Para que seja utilizado como tratamento alternativo, devem ser realizados novos estudos com relação à composição e propriedades da geoprópolis, já que foram obtidos resultados divergentes nas diferentes metodologias utilizadas.

\section{NOTAS INFORMATIVAS}

Este trabalho, protocolado $\mathrm{n}^{\circ}$ 0245/2008, foi aprovado pela Comissão de Ética no Trato com Animais da FESO, em reunião ordinária realizada em 13/02/2009.

\section{REFERÊNCIAS}

BATISTA, C.G.; COELHO, S.G.; RABELO, E.; LANA, A.M.Q.; CARVALHO, A.U.; REIS, R.B.; SATURNINO,H.M.. Desempenho e saúde de bezerras alimentadas com leite sem resíduo de drogas antimicrobianas ou leite de vacas tratadas contra mastite adicionado ou não de probiótico. Arquivo Brasileiro de Medicina Veterinária e Zootecnia,
Belo Horizonte, v.60, n 1, p.185-191, 2008.

COSTA,G.M.. Mamite bovina em rebanhos leiteiros da região sul do Estado de Minas Gerais. 2008. $123 f$. Tese (Doutor em Ciência Animal) Universidade Federal de Minas Gerais, Belo Horizonte.

COSTA, G.M.; SILVA, N.; ROSA, C.A.; FIGUEIREDO, H.C.P.; PEREIRA, U.P.. Mastite por leveduras em bovinos leiteiros do Sul do Estado de Minas Gerais, Brasil. Ciência Rural, Santa Maria, v.38, n.7, p.1938-1942, 2008.

COSTA, N.C.; ARAÚJO, R.L.; FREITAS, G.B.L. Homeopatia: um campo terapêutico fundamental no cuidado veterinário de animais de produção. Revista Salus-Guarapuava (PR), v.3; n.2, p. 75-89, 2009.

DUTRA, R. P.; NOGUEIRA, A.M.C.; MARQUES, R.R.O.; COSTA, M.C.P.; RIBEIRO,M.N.S.. A valiação farmacognóstica de geoprópolis de Melipona fasciculata Smith da Baixada maranhense, Brasil. Revista Brasileira de Farmacognosia, v. 18, n. 4, p. 557562, 2008.

HONORATO,L.A.. A interação hemeopatia em bovinos de leite. 2006. 120f. Dissertação (Mestrado em Agrossistemas) - Centro de Ciências Agrárias, Universidade Federal de Santa Catarina, Florianópolis.

LOGUERCIO, A.P.; GROFF, A.C.M.; PEDROZZO, A.F.; WITT, N.M.; SILVA, M.S.; VARGAS, A.C.. Atividade in vitro do extrato de própolis contra agentes bacterianos da mastite bovina. Pesquisa Agropecuária Brasileira, v.41, n.2, p.347-349, 2006.

LUSTOSA, S.R.; GALINDO, A.B.; NUNES, L.C.C.; RANDAU, K.P.; ROLIM NETO, P.J.. Própolis: atualizações sobre a química e a farmacologia. 
Revista Brasileira de Farmacognosia, v.18, n.3, p.447-454, 2008.

MIORIM, P.L.; LEVY JR, N.C.; CUSTODIO, A.R.; BRETZ, W.A.; MARCUCCI, M.C.. Antibacterial activity of honey and propolis from Apis mellifera and Tetragonisca angustula against Staphylococcus aureus. Journal of Applied Microbiology, v.95, n.5, p. 913-920, 2003.

MÜLLER, E.E.. Qualidade do leite, células somáticas e prevenção da mastite. In: SIMPÓSIO SOBRE SUSTENTABILIDADE DA PECUÁRIA LEITEIRA NA REGIÃO SUL DO BRASIL, 2., 2002, Toledo. Anais... Toledo: NUPEL, 2002. p.206-217.

NADER FILHO, A.; FERREIRA, L.M.; AMARAL, L.A.; ROSSI JR, O.D.; OLIVEIRA, R.P.. Sensibilidade antimicrobiana dos Staphylococcus aureus isolados no leite de vacas com mastite. Arquivos do Instituto Biológico, v.74, n.1, p.1-4, 2007.

PARK, Y.K.; IKEGAKIM, M.; ABREU, J.A.S.; ALCICl, N.M.F.. Estudo da preparação dos extratos de própolis e suas aplicações. Ciência e Tecnologia de Alimentos, v.18, n.3, p.313-318, 1998.

PINTO, M.S.. Efeito antimicrobiano de própolis verde do Estado de Minas Gerais sobre bactérias isoladas do leite de vacas com mastite. 2000. 92f. Dissertação (Mestrado em Medicina Veterinária) - Universidade Federal de Viçosa, Viçosa.

PINTO, M.S.; FARIA, J.E.; MESSAGE, D.; CASSINI, S.T.A.; PEREIRA, C.S., GIOSO, M.M.. Efeito de extratos de própolis verde sobre bactérias patogênicas isoladas do leite de vacas com mastite. Brasilian Journal of Veterinary Research and Animal Science, v.38, n.6, p.278-283, 2001.

RIBEIRO, M.G.; GERALDO, J.S.; LANGONI, H.; LARA, G.H.B.;
SIQUEIRA, A.K.; SALERNO, T.; FERNANDES, M.C. Microrganismos patogênicos, celularidade e resíduos de antimicrobianos no leite bovino produzido no sistema orgânico. Pesquisa Veterinária Brasileira, v. 29, n.1, p.52-58, 2009.

SILVA, R.B.; LIMA, P.M.; FERRAZ, R.E.O.; ALVES, N.D.; FEIJÓ, F.M.C.. Efeito "in vitro" de extrato alcoólico de própolis e geoprópolis sobre bactérias patogênicas isoladas de leite bovino mastítico. Revista CFMV, n.43, p. 4854, 2008.

SOUSA, J.P.B.; FURTADO, N.A.J.C.; JORGE, R.; SOARES, A.E.E.; BASTOS, J.K.. Perfis físico-químico e cromatográfico de amostras de própolis produzidas nas microrregiões de Franca (SP) e Passos (MG), Brasil. Revista Brasileira de Farmacognosia, João Pessoa, v.17, n.1, p.85-93, 2007.

TORRES, R.N.S.; LOPES, J.A.D.; MOITA NETO, J.M.; CITÓ, A.M.G.L.. Constituintes voláteis da própolis Piauiense. Química Nova, v.31, n.3, p.479-485, 2008.

TROVO, M.M.; SILVA, M.J.P; LEÃO, E.R..

Terapias alternativas/complementares no ensino público e privado: análise do conhecimento dos acadêmicos de enfermagem. Revista LatinoAmericana de Enfermagem, v.11, n.4, p.483-489, 2003.

VILLAVICENCIO, J.L.E.; ESPINOSA, A.P.; SERRANO, N.A.; TRUJILLO, A.G.; PEÑA, R.L.; PÉREZ, R.O.; AMADOR, B.M.. La ganedería orgânica, una alternativa de desarrollo pecuario para algunas regiones de México: uma revisión. Interciencia, v.32, n.6, p.385390, 2007.

YAMAMURA, A.A.M.; MULLER, E.E.; GIORDANO, L.G.P.; CONSENZA, M.; SILVA, P.F.N.; GODOY, A.. Isolamento de Prototheca spp. de vacas com mastite, de leite de tanques de 
expansão e do ambiente dos animais.

Semina: Ciências Agrárias, Londrina,

v.28, n.1, p.105-114, 2007. 